\title{
Specific inhibition of cyclooxygenase-2 (COX-2) expression by dietary curcumin in HT-29 human colon cancer cells
}

\author{
Ajay Goel, C. Richard Boland, Dharam P. Chauhan* \\ Division of Gastroenterology, Department of Medicine, The University of California San Diego, 9500 Gilman Drive, La Jolla, CA 92093-0688,
} USA

Received 12 February 2001; received in revised form 14 June 2001; accepted 15 June 2001

\begin{abstract}
Curcumin, a major yellow pigment and active component of turmeric, has been shown to possess anti-inflammatory and anticancer activities. Cyclooxygenase (COX)-2 plays an important role in colon carcinogenesis. To investigate the effect of curcumin on COX-2 expression, we treated HT-29 human colon cancer cells with various concentrations of curcumin. Curcumin inhibited the cell growth of HT-29 cells in a concentration- and time-dependent manner. Curcumin markedly inhibited the mRNA and protein expression of COX-2, but not COX-1. These data suggest that a non-toxic concentration of curcumin has a significant effect on the in vitro growth of HT-29 cells, specifically inhibits COX-2 expression, and may have value as a safe chemopreventive agent for colon cancer. (C) 2001 Elsevier Science Ireland Ltd. All rights reserved.
\end{abstract}

Keywords: Curcumin; Chemoprevention; Colon cancer; Cyclooxygenase-1; Cyclooxygenase-2

\section{Introduction}

Colon cancer is responsible for substantial mortality and morbidity in the Western world. Chemoprevention is a promising strategy because other therapies have not been effective in controlling either the high incidence or low survival rate of gastrointestinal cancers [1]. Recently, emphasis has been focused upon a variety of clinical and basic studies of chemoprevention using naturally occurring substances that are found in normal diets, since they might provide useful strategies to inhibit colon cancer with minimal toxicity [1]. Epidemiological studies suggest that dietary manipulations play an important role in reducing

\footnotetext{
This work was supported in part by a grant 'Complementary Therapies in Medicine' awarded to D.P.C.

* Corresponding author. Tel.: +1-858-822-0303; fax: +1-858822-0301.

E-mail address: dchauhan@ucsd.edu (D.P. Chauhan).
}

the cancer death rate as much as $90 \%$ [2]. Large number of minor food components and chemically related compounds block different stages of the carcinogenic process in animal models and some of these substances partially prevent or delay cancer formation in some high risk human populations [3-5].

Curcumin (diferuoylmethane) is a major yellow pigment in turmeric (curcuma longa) and is widely used as a spice. Curcumin exhibits a variety of pharmacological effects, and has been reported to have anti-inflammatory [6] and anti-tumor activities [7]. The anticancer properties of curcumin in animals have been demonstrated by the inhibition of tumor initiation induced by benz(a)pyrene and 7,12 dimethyl benz(a)anthracene [8] and tumor promotion induced by phorbol esters on mouse skin and on carcinogeninduced tumorigenesis in the stomach, duodenum and colon of mice $[9,10]$.

The anti-inflammatory properties of curcumin have 
recently been attributed, at least in part, to suppression of prostaglandin (PG) synthesis [6,7]. The conversion of arachidonic acid to PGs is catalyzed by two isoenzymes: the constitutively expressed cyclooxygenase$1(\mathrm{COX}-1)[11,12]$ and the inducible cyclooxygenase2 (COX-2) [13,14]. Both of these enzymes have been shown to be present in colon tumors of rodents and humans [15]. COX-1 is expressed in most tissues that generate PGs during their normal physiological functions, and its expression does not fluctuate in response to stimuli $[11,12]$. In contrast, COX-2 expression can be induced by various agents, including inflammatory cytokines, mitogens, reactive oxygen intermediates and many other tumor promoters [13,14,16,17]. Increased expression of COX-2 has been reported in many colorectal tumors and adenocarcinomas [18]. These findings have been substantiated by other studies, where investigators observed markedly elevated levels of COX-2 mRNA and protein in chemical carcinogen induced colonic tumors [15] and in adenomas taken from Min mice [18]. It has also been reported that the overexpression of COX-2 in intestinal epithelium leads to increased carcinogenesis, metastatic potential and angiogenesis [19-21].

Although the exclusive role of COX-2 in tumor development and progression has yet not been fully elucidated, numerous studies have demonstrated that COX-2 inhibitors can significantly reduce polyp formation and tumor growth in vivo [22]. Recently, Zhang et al. [23] have shown that curcumin inhibits the bile acid and phorbol ester-induced COX-2 expression in gastrointestinal cell lines. They also reported that curcumin can directly inhibit the COX2 activity. This indicates that like other inhibitors of COX-2, curcumin can also inhibit the expression of COX-2. But, the majority of the COX-2 inhibitors are non-specific such as aspirin and other non-steroidal anti-inflammatory drugs (NASAIDs) [24-26]. Due to their prolonged use and non-specific inhibition of COX-1, these agents can have severe side effects, such as gastrointestinal ulceration, bleeding, and renal toxicity [26,27]. In view of all these observations, increased attention has been diverted toward the development of specific COX-2 inhibitors, which might serve as potential non-toxic chemopreventive agents.

The present study was undertaken to investigate the specificity of curcumin in the inhibition of COX-2.
This study for the first time showed that curcumin specifically inhibits COX-2 but not COX-1 expression in HT-29 human colon cancer cells.

\section{Materials and methods}

\subsection{Materials}

The human colon adenocarcinoma cell line HT-29 was obtained from the American Type Culture Collection (ATCC, Rockville, MD). Cell culture reagents were purchased from Life Technologies Inc. (Grand Island, NY). Curcumin was obtained from Sigma Chemical Co., St. Louis, MO., and the stock solution was prepared by dissolving it in dimethyl sulfoxide (Sigma Chemical Co., St. Louis, MO) and stored in a brown bottle at $-20^{\circ} \mathrm{C}$ until used. All other chemicals were purchased from Sigma Chemical Co. (St. Louis, MO), unless otherwise stated.

\subsection{Cell culture and curcumin treatment}

HT-29 cells were cultured in $75 \mathrm{~cm}^{2}$ tissue culture flasks in Iscove's Modified Dulbecco's Medium (IMDM) (Life Technologies Inc., Grand Island, NY) containing $10 \%$ fetal bovine serum at $37^{\circ} \mathrm{C}$ in $5 \% \mathrm{CO}_{2}$ and $90 \%$ relative humidity. HT-29 cells were treated with various concentrations of curcumin $(5-75 \mu \mathrm{M})$ for $6,12,24,48$ and $72 \mathrm{~h}$.

\subsection{Cell viability}

Cell viability was assessed by the MTT (methyl thiazol tetrazolium bromide) assay as described previously [28]. Briefly, cells were plated in a 96 well microtiter plate at a density of $1 \times 10^{4}$ cells/ well in a final volume of $100 \mu$ IMDM medium. The cells were treated with varying doses of curcumin (5-75 $\mu \mathrm{M})$ for $6,12,24,48$ and $72 \mathrm{~h}$. After treatment the cells were incubated with MTT dye at a concentration of $50 \mu \mathrm{g} / 100 \mu \mathrm{l}$ for $3 \mathrm{~h}$ at $37^{\circ} \mathrm{C}$. The cells were thereafter lysed $(10 \%$ SDS in $0.01 \mathrm{~N} \mathrm{HCl})$ at $37^{\circ} \mathrm{C}$ for $12 \mathrm{~h}$ in the dark. Absorbance of the reduced intracellular formazon product was read at $570 \mathrm{~nm}$ in a microtiter plate reader. 


\subsection{RNA extraction and reverse transcription}

RNA was purified using the TRIzol reagent (Life Technologies Inc., Grand Island, NY). Purified RNA was suspended in diethyl pyrocarbonate (DEPC)-treated water and used for reverse transcription.

Equal quantities $(2.5 \mu \mathrm{g})$ of total cellular RNA from HT-29 cells were reverse transcribed using Moloney murine leukemia virus (MMLV) reverse transcriptase and hexamer primers (Superscript II/ One-step RT-PCR system; Life Technologies, Inc.) in a $20 \mu \mathrm{l}$ reaction volume.

Semi-quantitative RT-PCR for COX-1 and COX-2 was performed using primers synthesized based on an analytical procedure developed for human cyclooxygenases [29]. For human COX-1, the primers were; $5^{\prime}$ TGC CCA GCT CCT GGC CCG CCG CTT-3' (sense strand, bases 516-539) and 5'-GTG CAT CAA CAC AGG CGC CTC TTC-3' (antisense strand, bases 796819) which yielded a $304 \mathrm{bp}$ PCR product. For human COX-2, the primers were; $5^{\prime}$-TTC AAA TGA GAT TGT GGG AAA AT- $3^{\prime}$ (sense strand, bases 574596) and $5^{\prime}$-AGA TCA TCT CTG CCT GAG TAT CTT-3' (antisense strand, bases 855-878), yielding a 305 bp PCR product. Each PCR step consisted of a denaturation step $\left(94^{\circ} \mathrm{C}\right.$ for $\left.1 \mathrm{~min}\right)$, an annealing step $\left(60^{\circ} \mathrm{C}\right.$ for $\left.1 \mathrm{~min}\right)$ and an elongation step $\left(72^{\circ} \mathrm{C}\right.$ for $1 \mathrm{~min})$. There were a total of 30 cycles, followed by a final extension step $\left(72^{\circ} \mathrm{C}\right.$ for $\left.10 \mathrm{~min}\right)$ in a PTC 200 Thermal Cycler (MJ Research Inc., MA). $\beta 2 \mathrm{M}$ mRNA was also amplified in the same PCR reaction with COX-1 or COX-2, as an internal control using the following primers; 5'-ACC CCC ACT GAA AAA GAT GA-3' (sense strand) and $5^{\prime}$-ATC TTC AAA CCT CCA TGA TG- $3^{\prime}$ (antisense strand) resulting in a 120 bp PCR product. Following PCR amplification, an aliquot of the reaction mixture was electrophoresed on a $1 \%$ agarose gel with $0.5 \mu \mathrm{g} / \mathrm{ml}$ ethidium bromide, and the stained bands were visualized under UV light, photographed, digitized, and intensity was quantified using an Alfa Imager 4.4 (Alpha Innotech Corporation, San Leandro, CA). Percent mRNA expression was determined by normalizing the band intensity of COX-2 or COX-1 with $\beta 2 \mathrm{M}$ for each sample.

\subsection{Western immunoblotting}

Cell lysates were prepared by treating the HT-29 cells for 30 min in RIPA lysis buffer $(1 \times$ PBS, $1 \%$ Nonidet P-40, $0.5 \%$ sodium deoxycholate and $0.1 \%$ SDS). The lysates were sonicated twice for $20 \mathrm{~s}$ on ice and then centrifuged at $10000 \times g$ for $10 \mathrm{~min}$ to sediment the particulate material. Protein concentrations of the supernatant fractions were measured by the method of Lowry et al. [30]. SDS-PAGE was performed under reducing conditions on a $8 \%$ polyacrylamide gels as described by Laemmli [31]. The resolved proteins were transferred to nitrocellulose filters, and the filters were incubated with monoclonal COX-1 or COX-2 antibodies (Cayman Chemical Co., $\mathrm{MI})$. The membrane was subsequently incubated in a goat anti-mouse antibody conjugated to horseradish peroxidase (HRP) and developed by the ECL chemiluminescence system (Amersham, Arlington Heights, IL).

\section{Results}

\subsection{Curcumin inhibits growth of HT-29 cells}

The MTT assay was performed to assess the rate of proliferation of HT-29 human colon cancer cells after treatment with varying concentrations of curcumin $(0-75 \mu \mathrm{M})$ as a function of time (Fig. 1). The resulting growth curves show that curcumin has a concentration- and time-dependent inhibitory effect. The inhibitory effects of curcumin were more pronounced at higher doses, and also after 48 and $72 \mathrm{~h}$ of curcumin treatment. Maximum growth inhibitory effects of curcumin were observed at $75 \mu \mathrm{M}$ concentration after $72 \mathrm{~h}$ of treatment.

\subsection{Curcumin inhibits COX-2 mRNA expression in HT-29 cells}

We investigated the effects of curcumin on COX-2 mRNA expression in HT-29 human colon cancer cells (Fig. 2A). It was observed that curcumin markedly inhibited COX-2 mRNA expression even at the 5 $\mu \mathrm{M}$ concentration after $6 \mathrm{~h}$ of treatment. Inhibition in COX-2 mRNA expression was also observed at higher concentrations (10-75 $\mu \mathrm{M})$ of curcumin after $6 \mathrm{~h}$ of treatment. Maximum inhibition in COX-2 mRNA was observed at $75 \mu \mathrm{M}$ curcumin (Fig. 2A).

To determine if curcumin simultaneously inhibited the expression of COX-1, we studied its effect on the 


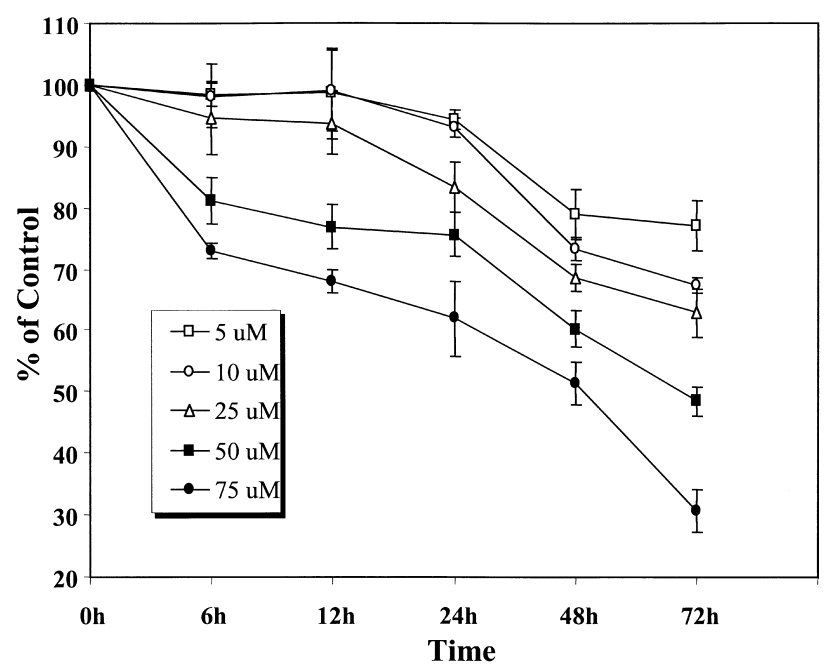

Fig. 1. Percent growth inhibition of HT-29 colon cancer cells after curcumin treatment $(0,5,10,25,50$, and $75 \mu \mathrm{M})$ for $6,12,24,48$ and $72 \mathrm{~h}$. Each point is a mean $\pm \mathrm{SD}$ of three independent experiments.

expression of COX-1 mRNA in HT-29 cells after similar treatments (Fig. 2B). Interestingly COX-1 mRNA expression remained unaltered with the curcumin treatments at concentrations up to $75 \mu \mathrm{M}$ (Fig. 2B).

The effect of different concentrations on the expression of COX-2 was also studied for 12, 24, 48 and $72 \mathrm{~h}$ (Fig. 3). Curcumin inhibited the levels of COX-2 mRNA in a concentration dependent manner but not in a time dependent manner (Fig. 3). The levels of COX-2 mRNA remained significantly inhibited for $72 \mathrm{~h}$ in curcumin treated HT-29 cells compared to untreated cells. The decreased levels of COX-2 mRNA rose when the same treatments were prolonged for longer period of time, but remained significantly lower (Fig. 3). These results suggest that the growth inhibitory effects of curcumin are not correlated with the inhibition of COX-2 expression. Fig. 4 shows the percent expression of COX-1 mRNA in HT-29 colon cancer cells treated with different concentrations of curcumin for $6,12,24,48$ and $72 \mathrm{~h}$. COX-1 mRNA did not show a significant reduction in curcumin treated HT-29 colon cancer cells (Fig. 4).

\subsection{Curcumin inhibits COX-2 protein expression}

Fig. 5 shows the Western immunoblots for COX-1 and COX-2 proteins after treatment of HT-29 cell with different concentrations of curcumin. We observed that curcumin markedly reduced the expression of COX-2 protein after $6 \mathrm{~h}$ of treatment at concentrations as low as $5 \mu \mathrm{M}$, and the expression was barely detectable at

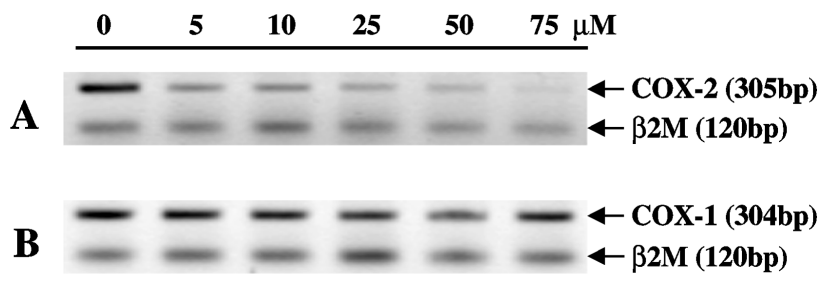

Fig. 2. Expression of COX-1 and COX-2 in HT-29 colon cancer cells treated with curcumin. (A) Agarose gel showing 305bp COX-2 and 120 bp $\beta 2 \mathrm{M}$ PCR products after $6 \mathrm{~h}$ of curcumin treatments in HT-29 cells. (B) Agarose gel showing $304 \mathrm{bp}$ COX-1 and 120 bp $\beta 2 \mathrm{M}$ PCR products after $6 \mathrm{~h}$ of curcumin treatments $(0-75 \mu \mathrm{M})$. 


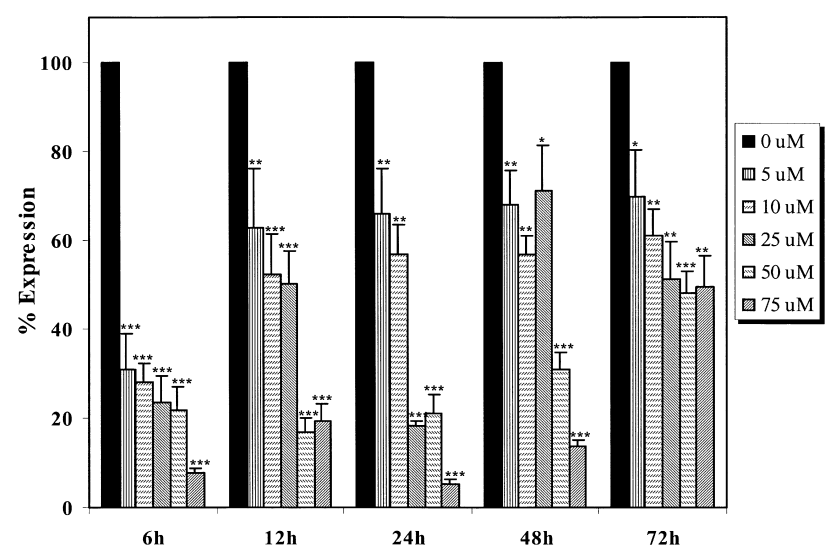

Fig. 3. Percent expression of COX-2 mRNA in curcumin treated HT-29 colon cancer cells. The cells were treated with $0-75 \mu \mathrm{M}$ curcumin for 6-72 h. Expression of COX-2 was studied by RT-PCR. Percent mRNA expression was determined by normalizing the band intensity of COX-2 with $\beta 2 \mathrm{M}$. The control $(0 \mu \mathrm{M})$ levels of COX-2 expression were considered as $100 \%$ and the treated levels were calculated as relative percentages for each experiment. Each bar represents the mean $\pm \mathrm{SD}$ of three experiments. $* P<0.05 ; * * P<0.01$ and $* * * P<0.001$ compared with controls.

the $75 \mu \mathrm{M}$ concentration (Fig. 5A). The reduced levels of COX-2 protein rose but remained markedly reduced when the curcumin treatments were prolonged for longer period (data not shown). Our observations that COX-2 protein concentrations were inhibited correlate with our COX-2 mRNA expression data, suggesting that no post-translational modifications of the mRNA transcript are necessary to account for the effect. COX1 protein expression was not reduced with curcumin treatments (Fig. 5B).

\section{Discussion}

The major focus of this study was to investigate the chemopreventive efficacy of curcumin as a possible inhibitor of COX-2 expression using the HT-29 human colon cancer cell model. Selection of curcumin for study as a chemopreventive agent was, in part, based on the evidence that curcumin has an inhibitory effect on arachidonic acid-induced inflammation and on arachidonic acid metabolism through the inhibition

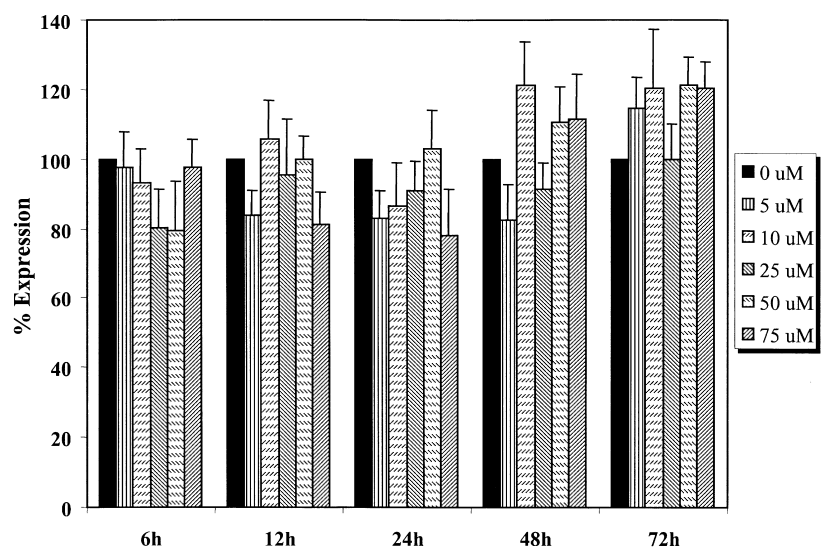

Fig. 4. Percent expression of COX-1 mRNA in curcumin treated HT-29 colon cancer cells. Cells were treated with curcumin and analyzed as described in Fig. 3. The control $(0 \mu \mathrm{M})$ levels of COX-1 were considered as $100 \%$ and the treated levels of COX-1 expression were calculated as relative percentages for each experiment. Each bar represents the mean \pm SD of three experiments. 


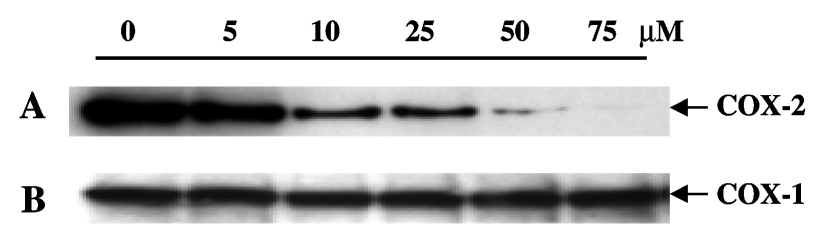

Fig. 5. Western blots illustrate the expression of COX-1 and COX-2 proteins. (A) $72 \mathrm{kDa}$ bands representing COX-2 protein after $6 \mathrm{~h}$ of curcumin treatments $(0-75 \mu \mathrm{M})$. (B) $70 \mathrm{kDa}$ bands representing COX-1 protein after $6 \mathrm{~h}$ of curcumin treatments $(0-75 \mu \mathrm{M})$.

of cyclooxygenase and lipooxygenase enzymes in mouse epidermis [6]. Furthermore, it has been shown previously that curcumin is a naturally occurring non-toxic, anti-inflammatory [6], antioxidant $[7,10]$ and anti-carcinogenic [10] agent. The outcome of this study is of significance as it clearly emphasizes that curcumin has the potential to specifically inhibit the expression of COX-2 at the message and protein level in HT-29 human colon cancer cells. The mechanisms of inhibition of COX-2 expression by curcumin are not well understood. HT-29 human colon cancer cells constitutively express COX-2 [32]. It seem that curcumin directly inhibits the expression of COX-2 in HT-29 colon cancer cells. This is in agreement with the previous study by Zhang et al. [23].

The results of this study confirm that curcumin is a potent inhibitor of growth in HT-29 human colon cancer cells. Similar effects of curcumin in arresting the rate of cell proliferation have been previously reported by workers in other colon cancer models $[7,10]$. Whether the growth inhibition of HT-29 colon cancer cells is due to the inhibition of COX-2 expression is not clear. We have studied the growth inhibitory effect of curcumin on COX-2 expressing and non-expressing colon cancer cell lines. Curcumin inhibits the growth of both types of cells (data not shown). These observations indicate that growth inhibition of colon cancer cells is independent of the inhibition of COX-2 expression. Hanif et al. [33] also reported that curcumin inhibits the growth of colon cancer cells independent of COX-2 expression.

Meanwhile, there is a increasing evidence suggesting that inhibitors of cyclooxygenase- 2 activity can be effective as anti-inflammatory agents and also in the prevention and treatment of colon cancer [22,34,35], because PGs are mediators of inflammation, and chronic inflammation predisposes to carcinogenesis $[26,27]$. Therefore, agents that are non-toxic and can inhibit COX-2 activity might be useful for the inhibition of colon carcinogenesis. Recently, inhibition of chenodeoxycholate and phorbol ester induced COX-2 transcription has been shown in curcumin treated gastrointestinal cell lines [23]. It is important to know the specificity of curcumin because the lack of selectivity for inhibition of COX-2 leads to unwanted side effects $[24,25]$.

COX is a bifunctional enzyme with cyclooxygenase and peroxidase activities [23,36]. The cyclooxygenase activity of COX is important for the initial conversion of arachidonic acid to prostaglandin $\mathrm{G}_{2}$, and the peroxidase activity of COX then converts it to prostaglandin $\mathrm{H}_{2}$ [36]. Finally, prostaglandin $\mathrm{H}_{2}$ is converted to other prostaglandins by a variety of tissue specific enzymes. These prostaglandins then exert their biological actions on these tissues [36]. NSAIDs do not inhibit the peroxidase function of the COX enzyme, which potentially limits their efficacy as anticancer agents [23]. Curcumin inhibits both the cyclooxygenase and peroxidase activities of the enzyme [23]. Therefore, curcumin may be superior to commonly used NSAIDs, which have anti-inflammatory and chemopreventive effects. Moreover, our study demonstrates for the first time that curcumin does not alter the expression of COX-1, so additional benefits may be gained by this agent over NSAIDs $[26,27]$. In conclusion, our study suggests that curcumin should be considered as a possible safe and nontoxic chemopreventive agent for colo-rectal cancer in humans.

\section{References}

[1] P. Greenwald, G.J. Kelloff, The role of chemoprevention in cancer control, in: B.W. Stewart, D. McGregor, P. Kleihus (Eds.), Principles of chemoprevention, IARC Scientific Publishers, Lyon, France, 1996, pp. 13-22.

[2] S.M. Plummer, K.A. Holloway, M.M. Manson, R.J. Munks, 
A. Kaptein, S. Farrow, L. Howells, Inhibition of cyclo-oxygenase 2 expression in colon cells by the chemopreventive agent curcumin involves inhibition of NF-kappaB activation via the NIK/IKK signalling complex, Oncogene 18 (1999) 60136020.

[3] K.H. Kraemer, J.J. DiGiovanna, A.N. Moshell, R.E. Tarone, G.L. Peck, Prevention of skin cancer in xeroderma pigmentosum with the use of oral isotretinoin, New Engl. J. Med. 318 (1988) 1633-1637.

[4] W.K. Hong, S.M. Lippman, L.M. Itri, D.D. Karp, J.S. Lee, R.M. Byers, S.P. Schantz, A.M. Kramer, R. Lotan, L.J. Peters, et al., Prevention of second primary tumors with isotretinoin in squamous-cell carcinoma of the head and neck, New Engl. J. Med. 323 (1990) 795-801.

[5] W.J. Blot, J.Y. Li, P.R. Taylor, W. Guo, S. Dawsey, G.Q. Wang, C.S. Yang, S.F. Zheng, M. Gail, G.Y. Li, et al., Nutrition intervention trials in Linxian, China: supplementation with specific vitamin/mineral combinations, cancer incidence, and disease-specific mortality in the general population, J. Natl. Cancer Inst. 85 (1993) 1483-1492.

[6] M.T. Huang, T. Lysz, T. Ferraro, T.F. Abidi, J.D. Laskin, A.H. Conney, Inhibitory effects of curcumin on in vitro lipoxygenase and cyclooxygenase activities in mouse epidermis, Cancer Res. 51 (1991) 813-819.

[7] C.V. Rao, A. Rivenson, B. Simi, B.S. Reddy, Chemoprevention of colon carcinogenesis by dietary curcumin, a naturally occurring plant phenolic compound, Cancer Res. 55 (1995) 259-266.

[8] M.T. Huang, Z.Y. Wang, C.A. Georgiadis, J.D. Laskin, A.H. Conney, Inhibitory effects of curcumin on tumor initiation by benzo [a] pyrene and 7,12-dimethylbenz [a] anthracene, Carcinogenesis 13 (1992) 2183-2186.

[9] M.T. Huang, R.C. Smart, C.Q. Wong, A.H. Conney, Inhibitory effect of curcumin, chlorogenic acid, caffeic acid, and ferulic acid on tumor promotion in mouse skin by 12-O-tetradecanoylphorbol-13-acetate, Cancer Res. 48 (1988) 5941-5946.

[10] M.T. Huang, Y.R. Lou, W. Ma, H.L. Newmark, K.R. Reuhl, A.H. Conney, Inhibitory effects of dietary curcumin on forestomach, duodenal, and colon carcinogenesis in mice, Cancer Res. 54 (1994) 5841-5847.

[11] D.L. DeWitt, W.L. Smith, Primary structure of prostaglandin $\mathrm{G} / \mathrm{H}$ synthase from sheep vesicular gland determined from the complementary DNA sequence, Proc. Natl. Acad. Sci. USA 85 (1988) 1412-1416.

[12] C. Yokoyama, T. Takai, T. Tanabe, Primary structure of sheep prostaglandin endoperoxide synthase deduced from cDNA sequence, FEBS Lett. 231 (1988) 347-351.

[13] W.L. Xie, J.G. Chipman, D.L. Robertson, R.L. Erikson, D.L. Simmons, Expression of a mitogen-responsive gene encoding prostaglandin synthase is regulated by mRNA splicing, Proc. Natl. Acad. Sci. USA 88 (1991) 2692-2696.

[14] D.A. Kujubu, B.S. Fletcher, B.C. Varnum, R.W. Lim, H.R. Herschman, TIS10, a phorbol ester tumor promoter-inducible mRNA from Swiss 3T3 cells, encodes a novel prostaglandin synthase/cyclooxygenase homologue, J. Biol. Chem. 266 (1991) 12866-12872.

[15] R.N. DuBois, A. Radhika, B.S. Reddy, A.J. Entingh, Increased cyclooxygenase-2 levels in carcinogen-induced rat colonic tumors, Gastroenterology 110 (1996) 1259-1262.

[16] W.L. Smith, R.M. Garavito, D.L. DeWitt, Prostaglandin endoperoxide $\mathrm{H}$ synthases (cyclooxygenases)-1 and -2, J. Biol. Chem. 271 (1996) 33157-33160.

[17] H. Sheng, J. Shao, S.C. Kirkland, P. Isakson, R.J. Coffey, J. Morrow, R.D. Beauchamp, R.N. DuBois, Inhibition of human colon cancer cell growth by selective inhibition of cyclooxygenase-2, J. Clin. Invest. 99 (1997) 2254-2259.

[18] C.S. Williams, C. Luongo, A. Radhika, T. Zhang, L.W. Lamps, L.B. Nanney, R.D. Beauchamp, R.N. DuBois, Elevated cyclooxygenase-2 levels in Min mouse adenomas, Gastroenterology 111 (1996) 1134-1140.

[19] M. Tsujii, R.N. DuBois, Alterations in cellular adhesion and apoptosis in epithelial cells overexpressing prostaglandin endoperoxide synthase 2, Cell 83 (1995) 493-501.

[20] M. Tsujii, S. Kawano, R.N. DuBois, Cyclooxygenase-2 expression in human colon cancer cells increases metastatic potential, Proc. Natl. Acad. Sci. USA 94 (1997) 3336-3340.

[21] M. Tsujii, S. Kawano, S. Tsuji, H. Sawaoka, M. Hori, R.N. DuBois, Cyclooxygenase regulates angiogenesis induced by colon cancer cells [published erratum appears in Cell 94 (1998) 271], Cell 93 (1998) 705-716.

[22] M. Oshima, J.E. Dinchuk, S.L. Kargman, H. Oshima, B. Hancock, E. Kwong, J.M. Trzaskos, J.F. Evans, M.M. Taketo, Suppression of intestinal polyposis in Apc delta716 knockout mice by inhibition of cyclooxygenase 2 (COX-2), Cell 87 (1996) 803-809.

[23] F. Zhang, N.K. Altorki, J.R. Mestre, K. Subbaramaiah, A.J. Dannenberg, Curcumin inhibits cyclooxygenase-2 transcription in bile acid- and phorbol ester-treated human gastrointestinal epithelial cells, Carcinogenesis 20 (1999) 445-451.

[24] E.A. Meade, W.L. Smith, D.L. DeWitt, Differential inhibition of prostaglandin endoperoxide synthase (cyclooxygenase) isozymes by aspirin and other non-steroidal anti- inflammatory drugs, J. Biol. Chem. 268 (1993) 6610-6614.

[25] J.K. Gierse, S.D. Hauser, D.P. Creely, C. Koboldt, S.H. Rangwala, P.C. Isakson, K. Seibert, Expression and selective inhibition of the constitutive and inducible forms of human cyclooxygenase, Biochem. J. 305 (1995) 479-484.

[26] B. Cryer, M. Feldman, Effects of very low dose daily, longterm aspirin therapy on gastric, duodenal, and rectal prostaglandin levels and on mucosal injury in healthy humans, Gastroenterology 117 (1999) 17-25.

[27] L.S. Simon, Biologic effects of nonsteroidal anti-inflammatory drugs, Curr. Opin. Rheumatol. 9 (1997) 178-182.

[28] T. Mosmann, Rapid colorimetric assay for cellular growth and survival: application to proliferation and cytotoxicity assays, J. Immunol. Methods 65 (1983) 55-63.

[29] T. Hla, K. Neilson, Human cyclooxygenase-2 cDNA, Proc. Natl. Acad. Sci. USA 89 (1992) 7384-7388.

[30] O.H. Lowry, N.J. Rosebrough, A.L. Farr, R.J. Randall, Protein measurement with the Folin phenol reagent, J. Biol. Chem. 193 (1951) 265-275.

[31] U.K. Laemmli, Cleavage of structural proteins during the assembly of the head of bacteriophage T4, Nature 227 (1970) 680-685. 
[32] J. Shao, H. Sheng, H. Inoue, J.D. Morrow, R.N. DuBois, Regulation of constitutive cyclooxygenase- 2 expression in colon carcinoma cells, J. Biol. Chem. 275 (2000) 3395133956.

[33] R. Hanif, L. Qiao, S.J. Shiff, B. Rigas, Curcumin, a natural plant phenolic food additive, inhibits cell proliferation and induces cell cycle changes in colon adenocarcinoma cell lines by a prostaglandin-independent pathway, J. Lab. Clin. Med. 130 (1997) 576-584.

[34] R. Chinery, R.D. Beauchamp, Y. Shyr, S.C. Kirkland, R.J. Coffey, J.D. Morrow, Antioxidants reduce cyclooxygenase-2 expression, prostaglandin production, and proliferation in colorectal cancer cells, Cancer Res. 58 (1998) 2323-2327.

[35] T. Kawamori, C.V. Rao, K. Seibert, B.S. Reddy, Chemopreventive activity of celecoxib, a specific cyclooxygenase- 2 inhibitor, against colon carcinogenesis, Cancer Res. 58 (1998) 409-412.

[36] W.B. Campbell, P.V. Halushka, Lipid-derived autocoids: eicosanoids and platelet-activating factor, in: Goodman, Gilman (Eds.), The Pharmacological basis of therapeutics, McGraw-Hill Companies, Inc, New York, NY, 1996, pp. 601-616. 